\title{
Direct Stenting Versus Direct Stenting Followed by Centered Beta-Radiation With Intravascular Ultrasound-Guided Dosimetry and Long-Term Anti-Platelet Treatment
}

\author{
Results of a Randomized Trial: Beta-Radiation \\ Investigation With Direct Stenting and Galileo in Europe (BRIDGE)
}

Patrick W. Serruys, MD, PHD, FACC, ${ }^{*}$ William Wijns, MD, † Georgios Sianos, MD, PHD, Ivan de Scheerder, MD, $\neq$ Paul A. van den Heuvel, MD, $§$ Wolfgang Rutsch, MD,\| Helmut D. Glogar, MD, Carlos Macaya, MD,\# Pierre H. Materne, MD, ${ }^{* *}$ Susan Veldhof, RN, †† Heike Vonhausen, PHD, †† Patricia C. Otto-Terlouw, MSc,㧊 Wim J. van der Giessen, MD, PHD* Rotterdam, the Netherlands; Aalst, Leuven, Antwerpen, Liege, and Diegem, Belgium; Berlin, Germany; Wien, Austria; Madrid, Spain

OBJECTIVES We sought to assess the efficacy of vascular brachytherapy (VBT) combined with stenting for the primary prevention of restenosis.

BACKGROUND Intravascular brachytherapy after stent implantation for de novo lesions has been abandoned for the present. We revisited this procedure by optimizing all procedural steps-the use of glycoprotein IIb/IIIa blockers, direct stenting, adequate radiation coverage, avoidance of edge damage, source centering, intravascular ultrasound-guided dosimetry, and continuation of a dual anti-platelet regimen for one year.

METHODS The Beta-Radiation Investigation with Direct stenting and Galileo in Europe (BRIDGE) study is a multicenter, randomized controlled trial evaluating the long-term efficacy of VBT with P-32 (20 Gy at $1 \mathrm{~mm}$ in the coronary wall) after direct stenting. The primary end point was angiographic intra-stent late loss; secondary end points were six months binary restenosis and neo-intimal hyperplasia. Patients $(\mathrm{n}=112)$ with de novo lesions $(2.5$ to $4.0 \mathrm{~mm}$ in diameter up to $15 \mathrm{~mm}$ long) were randomized to either VBT or no-VBT.

RESULTS At six months, intra-stent loss was 0.43 and $0.84 \mathrm{~mm}(\mathrm{p}<0.001)$ in the irradiated and control groups, respectively. Intra-stent neo-intimal volume was reduced from $36 \mathrm{~mm}^{3}$ to 10 $\mathrm{mm}^{3}$. However, in the irradiated group there were six late occlusions as well as eight restenoses outside the stented and peri-stented area at the fall-off dose edges of the irradiated area. Accordingly, the target vessel revascularization and major adverse cardiac and cerebrovascular events rates at one year in the VBT group $(20.4 \%$ and $25.9 \%$, respectively) were higher than in the control group (12.1\% and $17.2 \%$, respectively).

CONCLUSIONS Despite the optimization of pre-, peri-, and post-procedural factors and despite the relative efficacy of the brachytherapy for the prevention of the intra-stent neo-intimal hyperplasia, the clinical outcome of the irradiated group was less favorable than that of the control group. (J Am Coll Cardiol 2004;44:528-37) (C) 2004 by the American College of Cardiology Foundation

It has been shown that stents reduce restenosis by eliminating elastic recoil and negative remodeling, but they induce neo-intimal hyperplasia (1). Several randomized studies

\section{See page 538}

have confirmed the effectiveness of vascular brachytherapy (VBT) for the treatment of in-stent restenosis both with gamma (2-4) and beta (5-7) emitters, but its effectiveness

From the *Erasmus Medical Center, Rotterdam, The Netherlands; †Onze Lieve Vrouw Ziekenhuis, Aalst, Belgium; $¥ U Z$ Z Gasthuisberg, Leuven, Belgium; §Academisch Ziekenhuis Middelheim, Antwerpen, Belgium; \|Universitätsklinik Charité, Berlin, Germany; $\uparrow$ Allgemeines Krankenhaus der Stadt, Wien, Austria; \#Hospital Clínico San Carlos, Madrid, Spain; **CHR de la Citadelle, Liege, Belgium; † Guidant, Diegem, Belgium; and $\neq \neq$ Cardialysis BV, Rotterdam, The Netherlands.

Manuscript received November 21, 2003; revised manuscript received March 1, 2004, accepted March 2, 2004. for de novo lesions, especially in combination with the use of stents, remains contentious (8-10).

A dose-finding study with yttrium demonstrated a dosedependent reduction in restenosis in non-stented arteries (8), probably resulting from a beneficial effect of radiation on remodeling and an inhibitory effect on neo-intima formation $(11,12)$. This trial, however, did not suggest any favorable impact of beta radiation on restenosis in stented de novo lesions. Restenosis adjacent to the target site $(13,14)$ and late thrombotic events (15) were recognized as major limitations of VBT, especially in combination with the use of stents $(9,10)$.

Geographical miss (GM) and edge restenosis frequently were associated with dilation and stenting occurring after radiation treatment (16). Therefore, it was advocated to complete the percutaneous intervention treatment prior to 


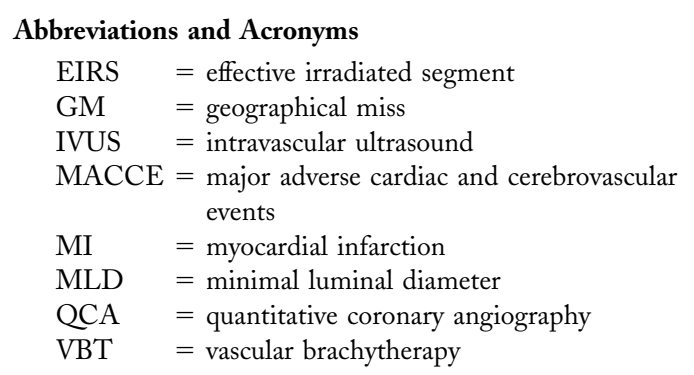

radiation to ensure complete radiotherapy coverage of the injury. Accordingly, direct stenting was viewed as an optimal approach to minimize the incidence of GM and edge restenosis. In addition, source centering and intravascular ultrasound (IVUS)-guided dosimetry, with theoretical advantages on dose delivery, were viewed as the methods of choice for radiotherapy treatment.

Because animal data have demonstrated increased thrombosis and the early presence of platelet activation after brachytherapy (17), the use of glycoprotein IIb/IIIa inhibitors was recommended as adjunctive therapy. Finally it was hypothesized that prolonged use of a dual anti-platelet medication reduces the incidence of late silent or thrombotic vessel occlusion $(9,10,18,19)$. Thus, the purpose of the current study was to evaluate the efficacy of centered intra-coronary beta irradiation with ${ }^{32} \mathrm{P} / \mathrm{Galileo}$ after direct stenting of de novo lesions in patients undergoing extended anti-platelet treatment with aspirin and clopidogrel.

\section{METHODS}

Study design. The Beta-Radiation Investigation with $\mathrm{Di}-$ rect stenting and Galileo in Europe (BRIDGE) trial is a multicenter, randomized, controlled clinical trial on the effect of brachytherapy after direct stenting. From February 2001 until March 2002, 112 patients were enrolled at 8 European centers. If the patient was eligible, a phone call was made to the central allocation service to register the patient, and the direct stenting procedure was performed. In cases of edge dissection or a stented length $>18 \mathrm{~mm}$, patients were subsequently not randomized. Once the direct stenting result was optimal based on quantitative coronary angiography (QCA) online criteria (residual diameter stenosis $<15 \%$ ), IVUS assessment was performed, and the patient was randomized during a second phone call, to either the VBT or control group.

All randomized patients underwent clinical follow-up at 1,6 , and 12 months and angiographic and IVUS follow-up at 6 months. An independent core laboratory assessed the angiographic and IVUS outcomes. Clinical end points were assessed by an independent masked end point committee. An independent data safety monitoring committee assessed the results with respect to patient safety at regular intervals. End points. The primary end point was the angiographic intra-stent late loss. The secondary end points were event- free survival at one year, defined as the absence of major adverse cardiac and cerebrovascular events (MACCE). Major adverse cardiac and cerebrovascular events were defined as the occurrence of cardiac death and/or cerebrovascular events and/or myocardial infarction (MI) (Q-wave infarction as defined by Minnesota Code, non-Q-wave MI two times the upper limit of normal of creatine kinase and an abnormal level of creatine kinase, $\mathrm{MB}$ fraction) and/or target vessel revascularization.

All deaths were considered cardiac unless they were unequivocally documented to be non-cardiac. "Target lesion revascularization" was defined as revascularization of the stented segment. "Target vessel revascularization" was defined as a revascularization of any segment of the randomized coronary artery. Additional secondary end points were MACCE, binary angiographic restenosis at six months, and neo-intimal hyperplasia at six months as assessed by IVUS. Power calculation and sample size. The sample size calculations were based on the results of the BElgium NEtherlands STENT (BENESTENT) II trial and the results of the dose-finding studies with the device under investigation $(8,20,21)$.

One hundred and twelve patients were randomized to two groups of equal size. This number of patients would lead to a power of at least $84 \%$ to detect a $50 \%$ decrease in loss (from 0.80 in the control group to 0.40 in the treated group) with a two-sided type I error rate of 0.05 .

Patient selection. Major inclusion criteria were: de novo lesions in one or two native vessels with a reference diameter of 2.5 to $4.0 \mathrm{~mm}$ and a lesion length of $15 \mathrm{~mm}$ suitable for direct stenting; stable (Canadian Cardiovascular Society class I, II, III, or IV) or unstable angina pectoris (Braunwald class I to III, B to C); or documented silent ischemia. Major exclusion criteria were: any $\mathrm{MI}$ within three days before inclusion and/or lack of normalization of the creatine phosphokinase; previous Q-wave MI in the territory supplied by the vessel to be treated and a large akinetic area in the same territory; stroke/gastro-intestinal bleeding within six months; ejection fraction $<30 \%$; severe hepatic disease; previous mediastinal irradiation; or known intolerance or contraindication to aspirin, clopidogrel, or glycoprotein IIB/IIIA inhibitors. Angioplasty exclusion criteria were: total occlusion (Thrombolysis in Myocardial Infarction flow grade 0 ); stenting of each arm of a bifurcation; and intended angioplasty of the ostium of the left anterior descending and left circumflex coronary artery to avoid impeding the flow in the main stem with the centering catheter. Written informed consent was obtained before patients were admitted to the interventional suite.

Post-procedural anti-platelet treatment. By protocol, a dual (clopidogrel $75 \mathrm{mg}$ and acetylsalicylic acid $80 \mathrm{mg}$ daily) anti-platelet treatment was used up to 11 months.

Study device: stent and radiation delivery system. The 18-mm MULTI-LINK RX TETRA Coronary Stent System (Guidant, Santa Clara, California) was used for direct 


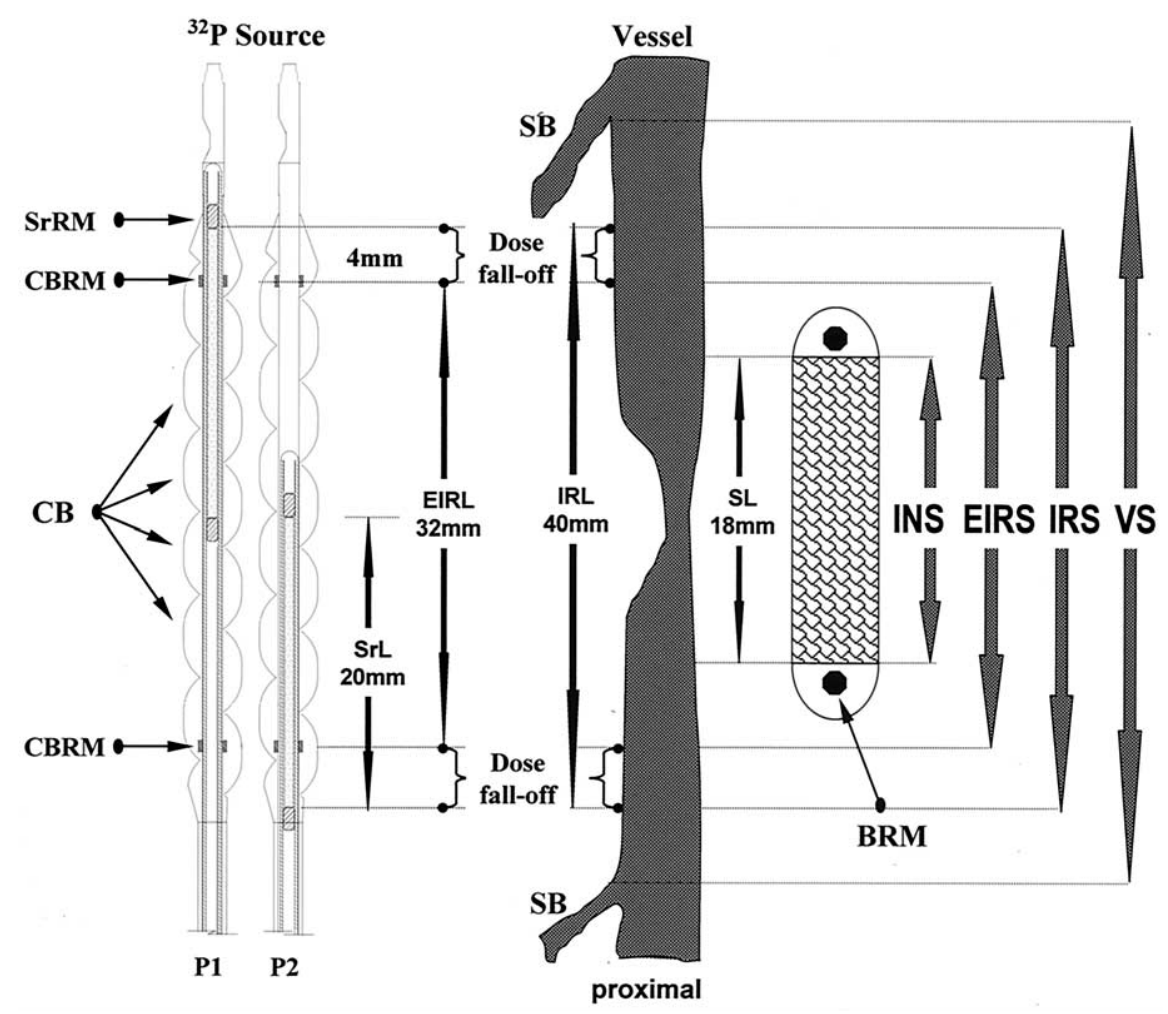

Figure 1. A schematic diagram of the tandem positioning of the ${ }^{32} \mathrm{P}$ radiation source and an irradiated coronary artery with the anatomical and dose-based sub-segment definition. $\mathrm{BRM}=$ balloon radiopaque marker; $\mathrm{CB}=$ centering balloon; $\mathrm{CBRM}=$ centering balloon radiopaque marker; EIRL $=$ effective irradiation length; EIRS = effective irradiated segment; INS = injured segment; IRL = irradiation length; IRS = irradiated segment; SB = side branch; $\mathrm{SL}=$ stent length; $\mathrm{SrL}=$ source length; $\mathrm{SrRM}=$ source radiopaque marker; VS = vessel segment.

stenting, and the GALILEO Intravascular Radiotherapy System (Guidant) was used for VBT.

The GALILEO Intravascular Radiotherapy System comprises the ${ }^{32} \mathrm{P}$ 0.018-inch source wire, a centering catheter, and the GALILEO source delivery unit. The source delivery unit is a high-dose rate afterloader designed specifically for coronary radiotherapy. It has a computercontrolled source wire handling device, which automatically advances the source wire to the most distal position of the centering catheter and subsequently moves to the next more proximal position in 20-mm increments (known as "steps"). Thus, the source wire makes two steps within the $32-\mathrm{mm}$ long spiral-designed centering balloon catheter that is inflated to a pressure of $4 \pm 1$ atmospheres and has a nominal diameter of $2.5,3.0$, or $3.5 \mathrm{~mm}$. Radiopaque markers (proximal and distal to the balloon) allow for the precise positioning of the centering catheter at the lesion site.

The appropriate diameter of the centering catheter is selected based on the intra-stent minimal luminal diameter (MLD) determined by online QCA. The dwell time required to deliver the prescribed dose (20 Gy at a depth of 1 $\mathrm{mm}$ in the vessel wall) is automatically computed, based on the average reference luminal diameter calculated from proximal and distal MLD acquired from online IVUS assessment. The length of the artery receiving full $20 \mathrm{~Gy}$ at $1 \mathrm{~mm}$ is $32 \mathrm{~mm}$, whereas the whole radiated length is 40 $\mathrm{mm}(2 \times 20 \mathrm{~mm})$. Fractionation of the treatment was required in three patients.

QCA evaluation. Quantitative coronary angiography was performed by means of the CAAS II analysis system (Pie Medical BV, Maastricht, Netherlands). A methodological approach, previously reported $(9,14,16,22)$, was used to accurately depict the "geographic" relationship between the stent and the radioactive source, and the following subsegments were defined (Fig. 1):

- Stented segment-defined by the radiopacity of the MULTI-LINK RX TETRA coronary stent.

- Peri-stent segments-defined by a length of $5 \mathrm{~mm}$ proximal and distal to the stent edge.

- Irradiated segment-defined as the segment encompassed by the inner edge of the radiopaque markers of the source wire. Two sub-segments of the irradiated segment are identified:

1. Effective irradiated segment (EIRS)—the segment (32 $\mathrm{mm})$ receiving full prescribed therapeutic radiation dose ( $90 \%$ isodose) is shorter than the irradiated segment $(40 \mathrm{~mm})$ as a result of the dose fall-off.

2. Edge (dose fall-off) segments-vessel segments at the extremities of the irradiation source that do not receive the full therapeutic radiation dose. The length of each edge segment is approximately $4 \mathrm{~mm}$. 


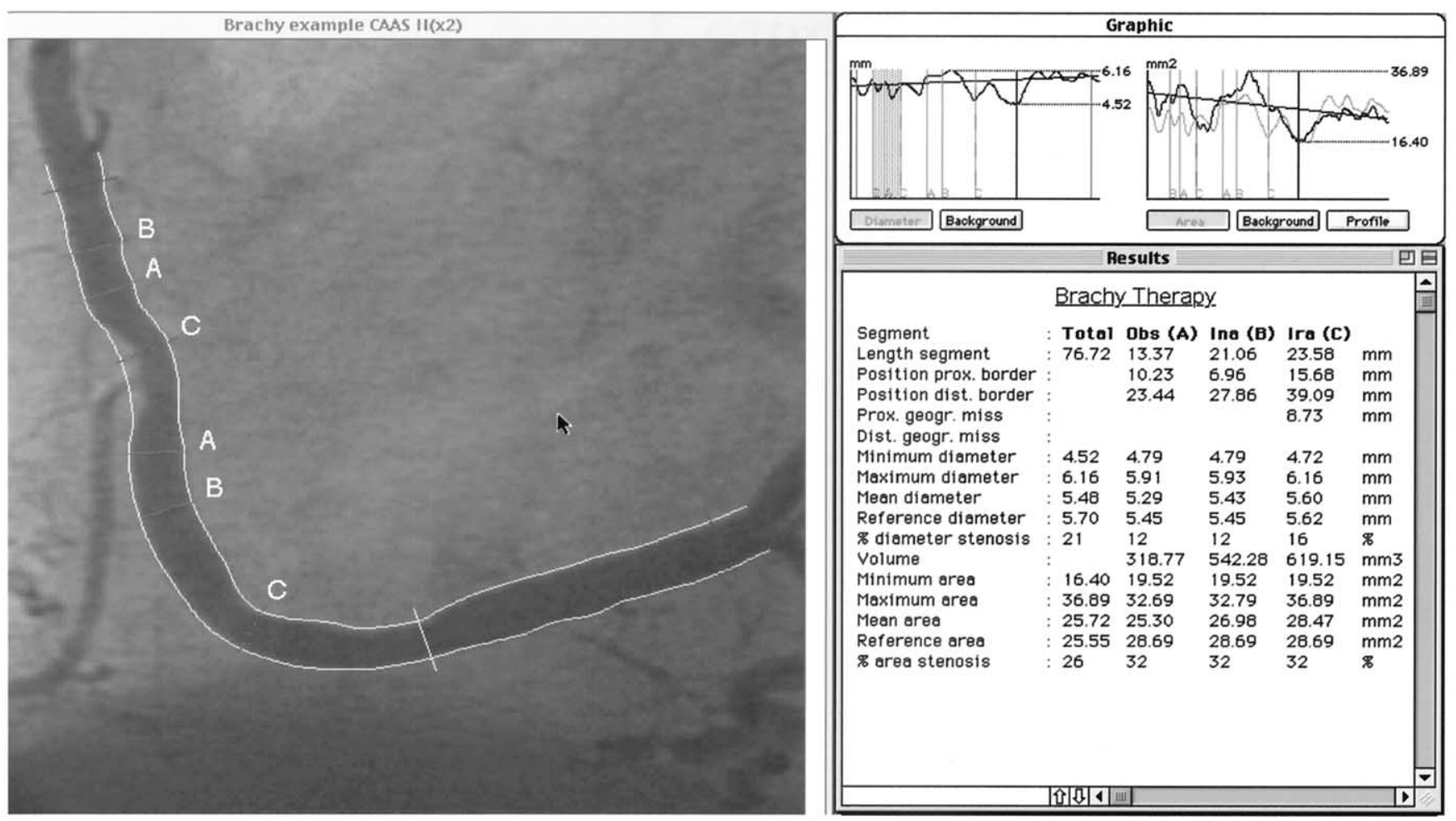

Figure 2. An example of quantitative coronary angiography depicting the automatic assessment of the anatomic relationship between the obstructed (A), the injured (B), and the irradiated (C) sub-segments, which allows the quantitative assessment of the length of the geographical miss, $8.73 \mathrm{~mm}$ at the proximal edge in this case.

- Vessel segment analysis—segment bordered by angiographically visible side branches encompassing lesion, stent, and radiation source.

- GM segment-this segment is present when the length of the stented and peri-stent segments $(28 \mathrm{~mm})$ are not covered by the EIRS (Figs. 2 and 3).

The above segment lengths were automatically measured by a customized software package specifically designed for the assessment of brachytherapy treatment. With this software, the anatomic relationship between the various (dose-related) sub-segments is automatically assessed, allowing the quantitative assessment of the length of the GM (Fig. 2).

At follow-up, the detection of any diameter stenoses $>50 \%$ in the analyzed vessel segment was performed by analysts who were blinded to the allocated treatment. Subsequently, the boundaries of the above-mentioned subsegments were superimposed on matched angiographic views using transparent sheets to locate the site of the MLD with respect to the irradiated area $(9,14,16,22)$.

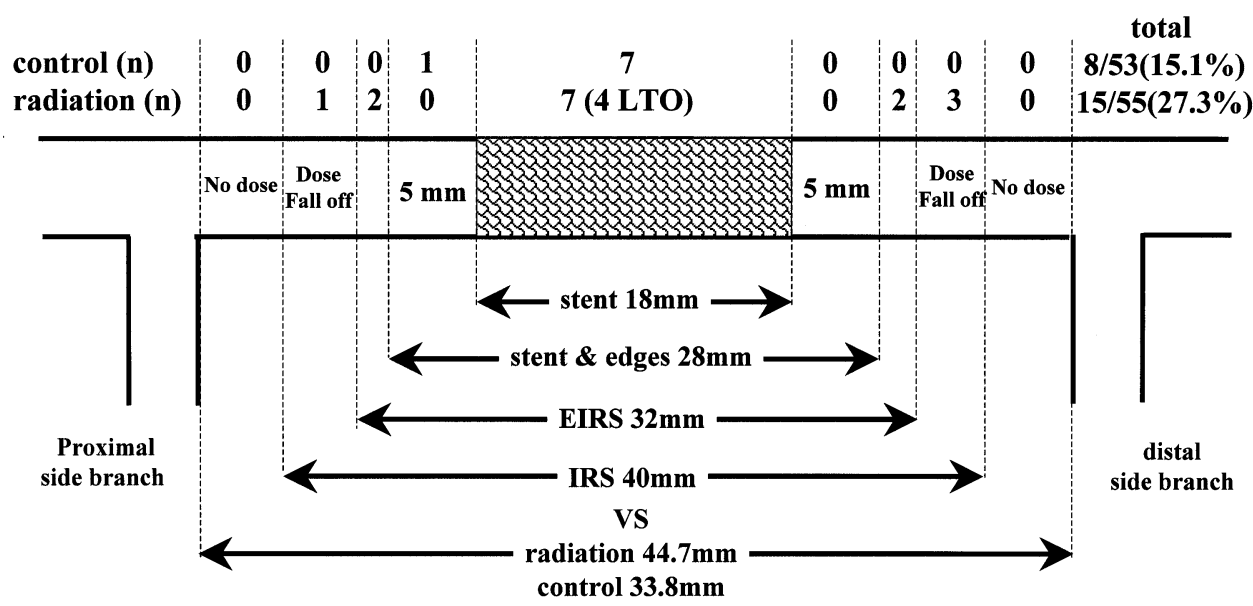

Figure 3. Location of the minimal luminal diameter at six months follow-up ( \pm 4 weeks) in patients with $>50 \%$ diameter stenoses in relation to the dose-based sub-segments. Four instances of late total occlusion (LTO) were documented at the time of the angiographic follow-up, and two occurred later. EIRS = effective irradiated segment; IRS = irradiated segment; VS = vessel segment. 
Table 1. Baseline Clinical and Angiographic Characteristics (Intention to Treat)

\begin{tabular}{|c|c|c|}
\hline & $\begin{array}{c}\text { Irradiation } \\
(\mathrm{n}=54 \text { Patients), } \mathrm{n}(\%)\end{array}$ & $\begin{array}{c}\text { No Irradiation } \\
(\mathrm{n}=58 \text { Patients), } \mathrm{n}(\%)\end{array}$ \\
\hline Age, yrs (mean $\pm \mathrm{SD})$ & $61.2 \pm 10.5$ & $61.6 \pm 10.5$ \\
\hline Gender, male & $41(75.9 \%)$ & $48(82.8 \%)$ \\
\hline Previous MI & $16(29.6 \%)$ & $19(32.8 \%)$ \\
\hline Diabetes mellitus & $8(14.8 \%)$ & $13(22.4 \%)$ \\
\hline Hypertension & $32(59.3 \%)$ & $31(53.4 \%)$ \\
\hline Current smoker & $12(22.6 \%)$ & $12(21.1 \%)$ \\
\hline \multicolumn{3}{|l|}{ Angina pectoris* } \\
\hline CCS class I & $6(11.1 \%)$ & $5(8.6 \%)$ \\
\hline CCS class II & $21(38.9 \%)$ & $19(32.8 \%)$ \\
\hline CCS class III & $10(18.5 \%)$ & $15(25.9 \%)$ \\
\hline CCS class IV & $0(0.0 \%)$ & $1(1.7 \%)$ \\
\hline Glycoprotein IIb/IIIa inhibitors & $51(94.4 \%)$ & $55(94.8 \%)$ \\
\hline \multicolumn{3}{|l|}{ Target coronary artery } \\
\hline LAD & $27(50.0 \%)$ & $28(48.3 \%)$ \\
\hline $\mathrm{RCA}$ & $31(57.4 \%)$ & $25(43.1 \%)$ \\
\hline LCX & $16(29.6 \%)$ & $23(39.7 \%)$ \\
\hline Lesion type & $\mathrm{n}=57$ lesions & $\mathrm{n}=59$ lesions \\
\hline A & $3(5.3 \%)$ & $1(1.7 \%)$ \\
\hline B1 & $21(36.8 \%)$ & $20(33.9 \%)$ \\
\hline B2 & $33(57.9 \%)$ & $38(64.4 \%)$ \\
\hline $\mathrm{C}$ & $0(0.0 \%)$ & $0(0.0 \%)$ \\
\hline Reference vessel diameter (mm) & $2.83 \pm 0.59$ & $2.87 \pm 0.49$ \\
\hline Lesion length $(\mathrm{mm})$ & $11.50 \pm 3.85$ & $11.73 \pm 5.42$ \\
\hline
\end{tabular}

Quantitative IVUS. Post-procedure and six-month followup stented vessel segments were examined with mechanical intravascular ultrasound (Cardio Vascular Imaging System, CVIS, Sunnyvale, California) using automated pullback at 0.5 $\mathrm{mm} / \mathrm{s}$. A coronary segment beginning $5 \mathrm{~mm}$ distal to and extending $5 \mathrm{~mm}$ proximal to the stented segment also was examined. A computer-based contour detection program was used for automated three-dimensional reconstruction of the stented segment. Lumen, stent boundaries, and external elastic membrane were detected using a minimum-cost algorithm. Total vessel volume (TVV), stent volume (SV), and lumen volume (LV) were calculated according to Simpson's rule. Total plaque volume, plaque volume behind the stent struts, and neo-intimal hyperplasia were calculated as TVV - LV, TVV - SV, SV - LV, respectively. Percentage obstruction volume was calculated as neo-intimal volume/stent volume $X$ 100. Feasibility, reproducibility, and inter- and intra-observer variability of this system have been validated in vitro and in vivo $(23,24)$.

Statistical analysis. The primary analysis was performed according to the intention-to-treat principle (all randomized patients), and the QCA end point was assessed on a per-lesion basis. A secondary per-protocol analysis was performed; patients who did not receive brachytherapy treatment as planned were excluded.

Continuous parameters were presented as mean values and standard deviations, and discontinuous parameters as percentages. Continuous parameters were compared using the Student $t$ test, whereas binary parameters were compared using the
Fisher exact test. Patient survival curves were constructed according to the Kaplan-Meier method. The Wilcoxon rank sum test was applied to evaluate the difference in hierarchical ranking between the two groups. The statistical significance of all tests was defined at the $\mathrm{p}<0.05$ level.

\section{RESULTS}

Patient baseline characteristics. Table 1 shows the baseline clinical and angiographic characteristics of each study group (54 patients with 57 lesions in the irradiation group versus 58 patients with 59 lesions in the control group). The number of diabetic patients enrolled in the irradiated and control groups were $8(14.8 \%)$ and 13 (22.4\%), respectively. The majority of patients were elective cases in functional class II or III, with a lesion Type B1/B2. In each group, 95\% of the patients received abciximab.

Serial QCA analyses. STENT AND PERI-STENT SEGMENTS. A total of 116 lesions were randomized: 57 lesions were allocated to irradiation, and 59 to control. Quantitative angiographic follow-up was available in 55 lesions allocated to irradiation, and 53 allocated to conventional treatment. Three lesions in the irradiated group did not receive the allocated treatment: one lesion could not be crossed with the delivery catheter, one lesion could not be irradiated because of a technical defect, and one lesion occluded before irradiation. In an intention-to-treat analysis, the in-stent late loss was reduced from $0.84 \pm 0.46$ to $0.43 \pm 0.75 \mathrm{~mm}(\mathrm{p}<0.001)$. Although the primary end point of the study was reached, the in-stent 
Table 2. Serial QCA Analyses (Intention to Treat)

\begin{tabular}{lccc}
\hline & $\begin{array}{c}\text { Irradiation } \\
\text { (55 Lesions) }\end{array}$ & $\begin{array}{c}\text { No Irradiation } \\
\text { (53 Lesions) }\end{array}$ & p \\
\hline In-stent & & & \\
MLD post (mm) & $2.66 \pm 0.44$ & $2.69 \pm 0.40$ & 0.68 \\
MLD follow-up (mm) & $2.23 \pm 0.82$ & $1.85 \pm 0.52$ & 0.006 \\
Late loss (mm) & $0.43 \pm 0.75$ & $0.84 \pm 0.46$ & 0.001 \\
DS follow-up (\%) & $23 \pm 25$ & $30 \pm 14$ & 0.07 \\
Restenosis, n (\%) & $7(12.7 \%)$ & $7(13.2 \%)$ & 1.00 \\
Edges & & & \\
Prox MLD post (mm) & $2.50 \pm 0.61$ & $2.71 \pm 0.62$ & 0.09 \\
Prox MLD follow-up (mm) & $2.49 \pm 0.60$ & $2.37 \pm 0.55$ & 0.001 \\
Prox late loss (mm) & $0.01 \pm 0.48$ & $0.34 \pm 0.50$ & 1.00 \\
Prox restenosis, $\mathrm{n}(\%)$ & $0(0.0 \%)$ & $1(1.9 \%)$ & 0.09 \\
Distal MLD post (mm) & $2.10 \pm 0.58$ & $2.28 \pm 0.45$ & 0.21 \\
Distal MLD follow-up (mm) & $1.99 \pm 0.61$ & $2.12 \pm 0.45$ & 0.77 \\
Distal late loss (mm) & $0.13 \pm 0.57$ & $0.16 \pm 0.33$ & \\
Distal restenosis, $\mathrm{n}(\%)$ & $0(0.0 \%)$ & $0(0.0 \%)$ & $\mathrm{NA}$ \\
Irradiated segment & & & $\mathrm{NA}$ \\
MLD (mm) & $1.77 \pm 0.71$ & $\mathrm{NA}$ & $\mathrm{NA}$ \\
DS follow-up (\%) & $37.87 \pm 21.49$ & $\mathrm{NA}$ & \\
Restenosis, n (\%) & $11(21.6 \%)$ & $1.71 \pm 0.45$ & 0.19 \\
Vessel segment & & $33 \pm 1.3$ & 0.001 \\
MLD (mm) & $1.57 \pm 0.65$ & $8(15.1 \%)$ & 0.16 \\
DS follow-up (\%) & $44 \pm 20$ & \\
Restenosis rate, $\mathrm{n}(\%)$ & $15(27.3 \%)$ & quantitative coronary angiography.
\end{tabular}

restenosis rates were similar; $12.7 \%$ (7 of 55; including 4 total occlusions) in the irradiated group versus $13.2 \%$ (7 of 53) in the control group. There was one patient with peri-stent restenosis in the control group (proximal edge), increasing restenosis to $15.1 \%$, and none in the irradiated group. The location of the MLD in patients with restenosis at follow up is presented in Figure 3.

If the three lesions that did not receive the irradiation allocated treatment were deregistered from the intentionto-treat analysis (per protocol analysis), then the late loss was reduced to $0.38 \pm 0.71 \mathrm{~mm}$ and the restenosis rate to $9.6 \%$. Irradiation showed a beneficial effect in the intentionto-treat group on the late luminal loss at the proximal edge (Table 2).

ANALYZED VESSEL SEGMENT. At follow-up in the irradiated group, four additional sites with a diameter stenosis $>50 \%$ were found in the EIRS, whereas four other restenotic sites were located at the edges of the EIRS (dose fall-off segments; one proximal and three distal). This resulted in an overall restenosis rate of $27.3 \%$, whereas the restenosis rate in the control group remained $15.1 \%, \mathrm{p}=$ 0.16 (no restenosis outside the stented and peri-stent segments) (Fig. 3).

TOTAL OCCLUSIONS. Overall, six patients presented with a late total occlusion ( $>30$ days), four within the time window of angiographic follow-up (180 days \pm 30 days; 103, 158, 169 , and 171 days after irradiation) and two later (270 and 269 days after irradiation). In an intention-to-treat analysis, all six patients $(10.9 \%$ per lesion) were in the irradiated group $(p=0.03)$. In a per-protocol analysis, five $(9.6 \%)$ were in the irradiated group, and one (1.8\%) was in the control group $(p=0.10)$. All occlusions occurred within the stented segment. The two patients with occlusions outside the time window of the angiographic follow-up were not included in the QCA results at six months (Table 2). If included, the late loss and restenosis rates in the irradiated group were $0.51 \pm 0.85 \mathrm{~mm}$ and $16.4 \%$, respectively. There were no patients with a sub-acute thrombosis within the first 30 days after the procedure. Of the six total occlusions, two were late thrombotic (presented as acute MIs) and four were silent. Four of the six patients underwent repeat revascularization (one surgical and three percutaneous).

INCIDENCE OF GM AND LOCATION OF RESTENOSIS WITH RESPECT TO THE IRRADIATED SEGMENT. All 55 vessels were interpretable for the ascertainment of GM and/or location of restenosis outside the stent and peri-stent segments. The average length of GM was $4.68 \pm 1.80 \mathrm{~mm}$, with a range of 1.92 to $7.65 \mathrm{~mm}$. There were $12(21 \%)$ vessels with documented GM (10 proximal and 2 distal). Of these, one vessel was occluded, and three had a diameter stenosis $>50 \%$. Two of these were related because of the GM (13\% of the overall restenosis observed in the irradiated group), and one showed progression of a pre-existing plaque proximal $(12.12 \mathrm{~mm})$ to the irradiated area. Sixty percent of the GM (7 of 12 vessels) were related to post-radiation intervention because of complications (persistent spasm, local thrombus formation, edge dissection) and the other $40 \%$ (5 of 12) was the result of inappropriate coverage of the stented segment by the radiation source. All the later cases were marginal, and they were not related to restenosis. 
Table 3. IVUS Analyses (Intention to Treat)

\begin{tabular}{|c|c|c|c|c|}
\hline & & $\begin{array}{l}\text { Irradiation } \\
\text { (57 Lesions) }\end{array}$ & $\begin{array}{l}\text { No Irradiation } \\
\text { (57 Lesions) }\end{array}$ & $\mathbf{p}^{*}$ \\
\hline \multicolumn{5}{|l|}{ Stent } \\
\hline Stent length (mm) & Post & $18.2 \pm 1.2$ & $18.3 \pm 1.8$ & 0.60 \\
\hline Stent volume $\left(\mathrm{mm}^{3}\right)$ & Post & $156 \pm 43$ & $160 \pm 45$ & 0.69 \\
\hline Neo-intimal volume $\left(\mathrm{mm}^{3}\right)$ & $\mathrm{F} / \mathrm{Up}$ & $10 \pm 12$ & $36 \pm 26$ & $<0.001$ \\
\hline Change in PBS volumes $\left(\mathrm{mm}^{3}\right)$ & $\mathrm{F} / \mathrm{Up}_{\mathrm{p}}$ & $24 \pm 28$ & $14 \pm 37$ & 0.06 \\
\hline Obstruction volume (\%) & $\mathrm{F} / \mathrm{Up}$ & $5 \pm 6$ & $21 \pm 14$ & $<0.001$ \\
\hline \multicolumn{5}{|l|}{ Proximal edge } \\
\hline Change in EEM & & $4.45 \pm 15.82$ & $0.49 \pm 10.85$ & 0.23 \\
\hline Change in plaque volume $\left(\mathrm{mm}^{3}\right)$ & & $5.28 \pm 13.77$ & $2.40 \pm 9.04$ & 0.31 \\
\hline Change in luminal volume $\left(\mathrm{mm}^{3}\right)$ & & $-0.84 \pm 12.10$ & $-1.96 \pm 12.77$ & 0.71 \\
\hline \multicolumn{5}{|l|}{ Distal edge } \\
\hline Change in EEM & & $4.36 \pm 9.33$ & $0.91 \pm 9.89$ & 0.15 \\
\hline Change in plaque volume $\left(\mathrm{mm}^{3}\right)$ & & $6.93 \pm 7.41$ & $1.73 \pm 6.64$ & 0.004 \\
\hline Change in luminal volume $\left(\mathrm{mm}^{3}\right)$ & & $-2.56 \pm 9.27$ & $-0.82 \pm 10.67$ & 0.48 \\
\hline
\end{tabular}

IVUS. The serial IVUS volumetric analysis confirmed the inhibition of the intra-stent neo-intimal hyperplasia within the irradiated group when compared with control $(10 \pm 12$ $\mathrm{mm}^{3}$ vs. $\left.36 \pm 26 \mathrm{~mm}^{3} ; \mathrm{p}<0.001\right)$ with a concomitant reduction of the percentage volume obstruction from $21 \pm$ $14 \%$ to $5 \pm 6 \% ; \mathrm{p}<0.001$ (Table 3 ).

In addition, the change in the plaque behind the stent struts was greater in the irradiated group $(p=0.06)$ than in the control. However, at the proximal and distal edges of the irradiated group, there was an increase in plaque volume accompanied by a compensatory increase in the external elastic membrane volume (expansive remodeling), whereas both plaque and external elastic membrane volumes remained unchanged in the control group. The final result was that the luminal volume remained unchanged in both groups at follow-up.
MACE. Table 4 shows the hierarchical ranking of MACE up to 12 months as well as the incidence of revascularization procedures (event per patient and total count of events). With the exception of the target lesion revascularization, the control group scored better than the irradiated group because of less frequent restenosis outside the target site in either the irradiated segment or the target vessel segment. The MACE-free survival curves are presented in Figure 4.

\section{DISCUSSION}

The premises of the present trial were that in the stent era, with more than $85 \%$ to $90 \%$ of patients being stented, radiotherapy treatment has to demonstrate its efficacy as an adjunct to stent treatment of de novo lesions for primary

Table 4. Most Severe (Hierarchical) MACE, Revascularization Procedures (Event Per Patient), and Total Count of Cardiac Events Up to 12 Months

\begin{tabular}{|c|c|c|c|}
\hline & $\begin{array}{c}\text { Irradiation } \\
(\mathrm{n}=54 \text { Patients })\end{array}$ & $\begin{array}{c}\text { No Irradiation } \\
(\mathrm{n}=58 \text { Patients })\end{array}$ & $\mathbf{p}$ \\
\hline Death, n (\%) & $0(0.0)$ & $0(0.0)$ & $0.36 \dagger$ \\
\hline \multicolumn{4}{|l|}{ Myocardial infarction } \\
\hline Q-wave, n (\%) & $3(5.6)$ & $0(0.0)$ & \\
\hline Non-Q-wave, n (\%) & $3(5.6)$ & $3(5.2)$ & \\
\hline \multicolumn{4}{|l|}{ Revascularization procedures } \\
\hline CABG, n (\%) & $0(0.0)$ & $0(0.0)$ & \\
\hline TLR RPTCA, n (\%) & $2(3.7)$ & $5(8.6)$ & \\
\hline TVSR, non-TLR RPTCA, n (\%) & $6(11.1)$ & $1(1.7)$ & \\
\hline TEVR, non-TLR, non-TVSR RPTCA, n (\%) & $0(0.0)$ & $1(1.7)$ & \\
\hline MACE, n (\%)* & $14(25.9)$ & $10(17.2)$ & $0.36 \neq$ \\
\hline $\begin{array}{l}\text { Revascularization procedures, n (\%) (CABG and } \\
\text { PTCA, event per patient) }\end{array}$ & $11(20.4)$ & $7(12.1)$ & $0.31 \neq$ \\
\hline Total count of events, $n$ & 19 & 10 & $0.09 \S$ \\
\hline \multicolumn{4}{|c|}{$\begin{array}{l}\text { *Includes death, myocardial infarction, and revascularization. }+ \text { Wilcoxon rank sum test. } ¥ \text { The Fisher exact test (two-tail). §The } \\
\text { student } t \text { test. Total epicardial vessel revascularization (TEVR) is defined as a revascularization of any segment of the coronary } \\
\text { artery that was in physical contact with any component (guiding catheter, guidewire, balloon catheter, or stent) of the angioplasty } \\
\text { hardware during the initial (allocated) procedure. Target vessel segment revascularization (TVSR) is defined as a revasculariza- } \\
\text { tion occurring within the treated vessel segment as defined by angiographic core laboratory analysis. } \\
\text { CABG = coronary artery bypass graft; MACE = major adverse cardiac events; PTCA = percutaneous transluminal coronary } \\
\text { angioplasty; TLR = target vessel revascularization; RPTCA = repeat PTCA. }\end{array}$} \\
\hline
\end{tabular}




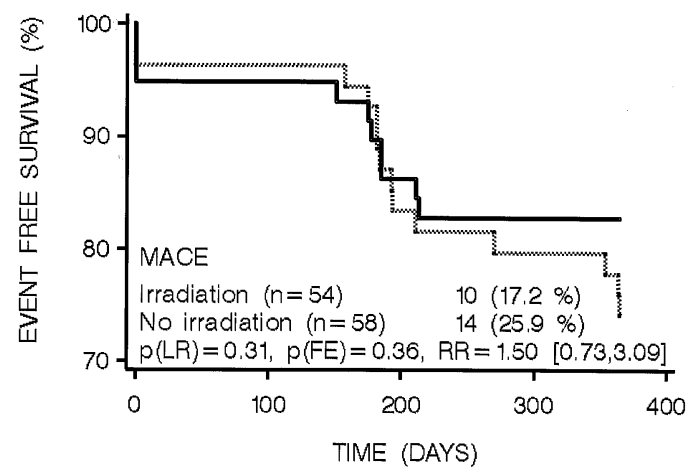

Figure 4. Event-free survival curves (Kaplan-Meier) at one year for the control and irradiated patients. MACE $=$ major adverse cardiac and cerebrovascular events; $p(F E)=p$ value Fisher exact test; $p(L R)=p$ value $\log$ rank test; $\mathrm{RR}=$ relative risk.

prevention of restenosis. A large percentage of the balloon "geographic miss" cases are the result of balloon dilation applied before or after stenting; to avoid this phenomenon, a strategy of direct stenting with post-dilation performed strictly inside the stent was mandated before any randomization. Also, radiation treatment had to be performed as the last interventional procedure.

An IVUS investigation was performed after stent deployment to exclude incomplete deployment and apposition and/or edge dissection. A centering delivery system and IVUS-guided dosimetry of $20 \mathrm{~Gy}$ at $1 \mathrm{~mm}$ in the artery wall were used to theoretically preclude any radiation failure due to an insufficient dose administration and/or inhomogeneous dose distribution. An effective irradiation source length $(32 \mathrm{~mm})$ almost twice as long as the stent length (18 $\mathrm{mm}$ ) was used to ensure adequate coverage of the lesion. Anti-thrombotic peri-procedural protection with glycoprotein IIb/IIIa inhibitors was systematically applied, and prolongation of the dual anti-platelet treatment was mandated for the prevention of late occlusion.

The main observations made in this study are the following: In-stent neo-intimal proliferation and restenosis are significantly reduced by beta irradiation. Peri-stent edge stenoses are eliminated by proper procedural technique and increased length of irradiation. Despite all efforts to reduce vascular damage and GM, total vessel analysis documents new stenosis toward the edges of the radioactive source (four within the effective irradiated segment, four at the edges). Despite peri-procedural administration of abciximab and thienopyridin for 11 months, vascular brachytherapy in patients with new stent implantation is associated with an excess of late coronary occlusion.

Previous observational and randomized trials with betabrachytherapy for de novo lesions. The Proliferation REduction with Vascular ENergy Trial (PREVENT) also used a centered beta-emitting ${ }^{32} \mathrm{P}$ source wire. In this small placebo-controlled, dose-finding study, the clinical and angiographic outcome was better in the irradiated patients (21). However, edge restenosis reduced the overall clinical benefit of radiotherapy. A $10 \%$ incidence of late vessel occlusion also was reported with the one-month administration of double anti-platelet therapy.

In the Beta Radiation In Europe (BRIE) registry, 149 patients received $14 \mathrm{~Gy}$ of beta radiation. Restenosis and MACE rates were $34 \%$ (9). In this trial, the problem of edge restenosis was related to the occurrence of GM (16). A 5.7\% late vessel occlusion rate was reported, and the prolongation of anti-platelet treatment reduced its incidence. Patients that received a new stent in combination with radiation had worse clinical and angiographic outcomes than patients who were treated with balloon angioplasty and radiotherapy. The same was observed during the European Dose-Finding study (8).

The BetaCath trial was the largest randomized trial of beta radiation and stenting in de novo lesions (951 patients). It failed to show any difference in the primary end point in the radiation arm compared with the control arm (10). The late vessel thrombosis, edge restenosis, and the incompatibility of radiation with the use of stents for de novo lesions were the main lessons learned from this study. However, this negative result could be attributed to the lack of source centering, low prescription radiation dose, and the high incidence of GM.

Edge restenosis. Restenosis at the edges of the radioactive source was first described after radioactive stent implantation and (25) was seen subsequently in all brachytherapy trials. By IVUS, edge restenosis is a combination of increase in plaque volume without adaptive remodeling $(26,27)$.

In concordance with known cell biological effects and animal data, low-dose radiation at the extremities of the source (dose fall-off) and angioplasty-induced vessel injury, referred to as "geographical miss," seem to play a key role in edge restenosis and treatment failure for beta (16) and gamma (28) brachytherapy. The fall-off dose at the source edges is an inherent characteristic of all sources, beta or gamma.

Safety margins. The safety margins after brachytherapy for avoidance of GM and edge restenosis have not yet been defined. Many factors, such as the extent of the peri-vascular injury (up to $10 \mathrm{~mm}$ away from a microscopic point of view) (29), the barotrauma caused by the balloons (up to $2.5 \mathrm{~mm}$ away from the actual stent margins) (30), the source displacement during the cardiac cycle (up to $5.4 \mathrm{~mm}$ ) (31), and the fall-off dose at the margins of each source, must be considered.

It has been proposed that for an 18-mm lesion treated with a $20-\mathrm{mm}$ balloon, a $39-\mathrm{mm}$ iridium source should be used (32). In an animal model, a safety margin of $14.5 \mathrm{~mm}$ was sufficient to eliminate edge restenosis (33). Recently a $10-\mathrm{mm}$ safety margin per vessel was found to have $95 \%$ specificity for avoidance of GM (34). As a simple rule, a ratio of one to two for the lesion to source length is advised. This advice was applied in the present trial, with the result of eliminating any significant loss in the peri-stent segment $(5 \mathrm{~mm}$ proximal, 5 $\mathrm{mm}$ distal). However, eight sites of restenosis were documented around the edges of the irradiated area. The physiopathological mechanism of narrowing remains elusive because no injury has been imparted on this vessel wall segment, and 
the spiraled balloon of the radiation therapy delivery system cannot be implicated in a potential traumatic injury, because it is slightly undersized, inflated at low pressure, and shorter than the radioactive source (centering balloon length $32 \mathrm{~mm}$ and radiation source length $40 \mathrm{~mm}[2 \times 20 \mathrm{~mm}])$. The only remaining explanatory hypothesis is the potential stimulating effect of a low dose on a pre-existing atherosclerotic plaque (35). Low-dose radiation ( $\pm 2 \mathrm{~Gy}$ ) has been shown to potentiate cellular metabolic activities and immunological responses in various tissues (36-39).

Late vessel occlusion. In the first brachytherapy trials, the phenomenon of late occlusion, silent or symptomatic, of the irradiated vessel became apparent (15). Initial clinical trials prescribed a combined anti-thrombotic treatment (aspirin and clopidogrel or ticlopidine) for two to four weeks after irradiation. First, they reported that most events occurred after discontinuation of the double anti-platelet treatment (9). In consequence, prolonged combined anti-thrombotic treatment was recommended. Two trials have addressed the issue of prolonged anti-platelet treatment for the prevention of late occlusion/thrombosis. In the Washington Radiation for In-Stent Restenosis trial (WRIST) (18), clopidogrel and aspirin were prescribed for 6 months (WRIST PLUS), and in WRIST 12 (19) for 12 months. Both showed good results at 6 months follow-up, but at 15 months, the incidence of occlusion/thrombotic rates were unacceptably high: 15.9\% in WRIST PLUS and 13.5\% in WRIST 12. Second, they reported that new stent implantation was related to late thrombosis both in de novo (40) and restenotic lesions $(9,10)$.

In the present study, six late occlusions occurred despite the use of prolonged dual anti-platelet treatment. Poor compliance with anti-platelet medication, edge dissection, and incomplete stent apposition at baseline were excluded as direct mechanisms of thrombosis or occlusion. The most likely explanation is long-term endothelial dysfunction and delayed vascular healing, two established drawbacks of vessel irradiation previously documented in animal models (41).

Study limitations. This study is a well-randomized study but not a double-blind trial, and the effect of a sham source on injured coronary segments has not been evaluated. Stent implantation was considered as the only source of injury. Minor injuries from guiding catheters, guide wires, or the radiation-centering catheter cannot be completely ruled out. Conclusions. Optimized application of vascular brachytherapy with adequate coverage of vascular injury and use of IVUS-guided dosimetry did succeed in preventing in-stent neo-intimal proliferation and peri-stent edge restenosis. However, the lower doses that are delivered at the fall-off zones, which is a phenomenon inherent in any brachytherapy source (short or long), seems to promote the progression of pre-existing plaque and results in new stenoses toward the edges of the irradiated segment. The increased radiation source length and dose were most likely responsible for the observed excess in vessel thrombosis despite prolonged anti-platelet medication. This narrow therapeutic window precludes any use of brachytherapy as a therapeutic tool for the primary prevention of restenosis in de novo lesions treated with bare metal stents.

Reprint requests and correspondence: Professor Patrick W. Serruys, Erasmus Medical Center, Thoraxcenter, Bd-406, Dr. Molewaterplein 40, 3015 GD, Rotterdam, The Netherlands. E-mail: p.w.j.c.serruys@erasmusmc.nl.

\section{REFERENCES}

1. Kuntz RE, Gibson CM, Nobuyoshi M, Baim DS. Generalized model of restenosis after conventional balloon angioplasty, stenting and directional atherectomy. J Am Coll Cardiol 1993;21:15-25.

2. Teirstein PS, Massullo V, Jani S, et al. Catheter-based radiotherapy to inhibit restenosis after coronary stenting. N Engl J Med 1997;336: 1697-703.

3. Waksman R, White RL, Chan RC, et al. Intracoronary gammaradiation therapy after angioplasty inhibits recurrence in patients with in-stent restenosis. Circulation 2000;101:2165-71.

4. Leon MB, Teirstein PS, Moses JW, et al. Localized intracoronary gamma-radiation therapy to inhibit the recurrence of restenosis after stenting. N Engl J Med 2001;344:250-6.

5. Waksman R, Bhargava B, White L, et al. Intracoronary beta-radiation therapy inhibits recurrence of in-stent restenosis. Circulation 2000; 101:1895-8.

6. Waksman R, Raizner AE, Yeung AC, Lansky AJ, Vandertie L. Use of localised intracoronary beta radiation in treatment of in-stent restenosis: the INHIBIT randomized controlled trial. Lancet 2002;359:551-7.

7. Popma JJ, Suntharalingam M, Lansky AJ, et al. Randomized trial of $90 \mathrm{Sr} / 90 \mathrm{Y}$ beta-radiation versus placebo control for treatment of in-stent restenosis. Circulation 2002;106:1090-6.

8. Verin V, Popowski Y, de Bruyne B, et al. Endoluminal beta-radiation therapy for the prevention of coronary restenosis after balloon angioplasty. The Dose-Finding Study Group. N Engl J Med 2001;344:243-9.

9. Serruys PW, Sianos G, van der Giessen W, et al. Intracoronary beta-radiation to reduce restenosis after balloon angioplasty and stenting; the Beta Radiation In Europe (BRIE) study. Eur Heart J 2002;23:1351-9.

10. Kuntz R, Speiser B, Joyal M. Clinical and angiographic outcomes after use of Sr-90 beta radiation for the treatment of de novo and restenotic coronary lesions. Paper presented at: Congress of the American College of Cardiology; March 2001; Orlando, Florida.

11. Sabate M, Serruys PW, van der Giessen WJ, et al. Geometric vascular remodeling after balloon angioplasty and beta-radiation therapy: a threedimensional intravascular ultrasound study. Circulation 1999;100:1182-8.

12. Meerkin D, Tardif JC, Crocker IR, et al. Effects of intracoronary beta-radiation therapy after coronary angioplasty: an intravascular ultrasound study. Circulation 1999;99:1660-5.

13. Sabate M, Costa MA, Kozuma K, et al. Geographic miss: a cause of treatment failure in radio-oncology applied to intracoronary radiation therapy. Circulation 2000;101:2467-71.

14. Sabate M, Costa MA, Kozuma K, et al. Methodological and clinical implications of the relocation of the minimal luminal diameter after intracoronary radiation therapy. Dose Finding Study Group. J Am Coll Cardiol 2000;36:1536-41.

15. Costa MA, Sabate M, van der Giessen WJ, et al. Late coronary occlusion after intracoronary brachytherapy. Circulation 1999;100:789-92.

16. Sianos G, Kay IP, Costa MA, et al. Geographical miss during catheter-based intracoronary beta-radiation: incidence and implications in the BRIE study. Beta-Radiation In Europe. J Am Coll Cardiol 2001;38:415-20.

17. Vodovotz Y, Waksman R, Kim WH, Bhargava B, Chan RC, Leon M. Effects of intracoronary radiation on thrombosis after balloon overstretch injury in the porcine model. Circulation 1999;100:2527-33.

18. Waksman R, Ajani AE, White RL, et al. Prolonged antiplatelet therapy to prevent late thrombosis after intracoronary gammaradiation in patients with in-stent restenosis: Washington Radiation for In-Stent Restenosis Trial plus 6 months of clopidogrel (WRIST PLUS). Circulation 2001;103:2332-5. 
19. Waksman R, Ajani AE, Pinnow E, et al. Twelve versus six months of clopidogrel to reduce major cardiac events in patients undergoing gamma-radiation therapy for in-stent restenosis: Washington Radiation for In-Stent restenosis Trial (WRIST) 12 versus WRIST PLUS. Circulation 2002;106:776-8.

20. Serruys PW, de Jaegere P, Kiemeneij F, et al. A comparison of balloon-expandable-stent implantation with balloon angioplasty in patients with coronary artery disease. Benestent Study Group. N Engl J Med 1994;331:489-95.

21. Raizner AE, Oesterle SN, Waksman R, et al. Inhibition of restenosis with beta-emitting radiotherapy: report of the Proliferation Reduction with Vascular Energy Trial (PREVENT). Circulation 2000;102:951-8.

22. Regar E, Kozuma K, Sianos G, Carlier SG, Serruys PW. Quantitative coronary angiography methodology in vascular brachytherapy. In Waksman R, editor. Vascular Brachytherapy. Armonk (NY): Futura Publishing Company, 2002:525-41.

23. von Birgelen $\mathrm{C}, \mathrm{Di}$ Mario $\mathrm{C}, \mathrm{Li} \mathrm{W}$, et al. Morphometric analysis in three-dimensional intracoronary ultrasound: an in vitro and in vivo study performed with a novel system for the contour detection of lumen and plaque. Am Heart J 1996;132:516-27.

24. Serruys PW, Degertekin M, Tanabe K, et al. Intravascular ultrasound findings in the multicenter, randomized, double-blind RAVEL (RAndomized study with the sirolimus-eluting VElocity balloon-expandable stent in the treatment of patients with de novo native coronary artery Lesions) trial. Circulation 2002;106:798-803.

25. Albiero R, Nishida T, Adamian M, et al. Edge restenosis after implantation of high activity (32)P radioactive beta-emitting stents. Circulation 2000;101:2454-7.

26. Kozuma K, Costa MA, Sabate M, et al. Three-dimensional intravascular ultrasound assessment of noninjured edges of beta-irradiated coronary segments. Circulation 2000;102:1484-9.

27. Mintz GS, Weissman NJ, Fitzgerald PJ. Intravascular ultrasound assessment of the mechanisms and results of brachytherapy. Circulation 2001;104:1320-5

28. Kim HS, Waksman R, Cottin Y, et al. Edge stenosis and geographical miss following intracoronary gamma radiation therapy for in-stent restenosis. J Am Coll Cardiol 2001;37:1026-30.

29. Levendag PC. Vascular brachytherapy new perspectives. London: Remedica Publishing, 1999:8-16.
30. Giap H, Teirstein P, Massullo V, Tripuraneni P. Barotrauma due to stent deployment in endovascular brachytherapy for restenosis prevention. Int J Radiat Oncol Biol Phys 2000;47:1021-4.

31. Giap HB, Bendre DD, Huppe GB, Teirstein PS, Tripuraneni P. Source displacement during the cardiac cycle in coronary endovascular brachytherapy. Int J Radiat Oncol Biol Phys 2001;49:273-7.

32. Tripuraneni P, Parikh S, Giap H, et al. How long is enough? Defining the treatment length in endovascular brachytherapy. Catheter Cardiovasc Interv 2000;51:147-53.

33. Cheneau E, Waksman R, Yazdi H, et al. How to fix the edge effect of catheter-based radiation therapy in stented arteries. Circulation 2002; 106:2271-7.

34. Syeda B, Siostrzonek P, Schmid R, et al. Geographical miss during intracoronary irradiation: impact on restenosis and determination of required safety margin length. J Am Coll Cardiol 2002;40:1225-31.

35. Cottin Y, Kollum M, Kolodgie FD, et al. Intravascular radiation accelerates atherosclerotic lesion formation of hypercholesteremic rabbits. Cardiovasc Radiat Med 2001;2:231-40.

36. Kojima S, Matsumori S, Ishida H, Yamaoka K. Possible role of elevation of glutathione in the acquisition of enhanced proliferation of mouse splenocytes exposed to small-dose gamma-rays. Int J Radiat Biol 2000;76:1641-7.

37. Chen SL, Cai L, Meng QY, Xu S, Wan H, Liu SZ. Low-dose whole-body irradiation (LD-WBI) changes protein expression of mouse thymocytes: effect of a LD-WBI-enhanced protein RIP10 on cell proliferation and spontaneous or radiation-induced thymocyte apoptosis. Toxicol Sci 2000;55:97-106.

38. Ibuki Y, Goto R. Contribution of inflammatory cytokine release to activation of resident peritoneal macrophages after in vivo low-dose gamma-irradiation. J Radiat Res (Tokyo) 1999;40:253-62.

39. Wang GJ, Cai L. Induction of cell-proliferation hormesis and cellsurvival adaptive response in mouse hematopoietic cells by whole-body low-dose radiation. Toxicol Sci 2000;53:369-76.

40. Waksman R, Bhargava B, Mintz GS, et al. Late total occlusion after intracoronary brachytherapy for patients with in-stent restenosis. J Am Coll Cardiol 2000;36:65-8.

41. Cheneau E, John MC, Fournadjiev J, et al. Time course of stent endothelialization after intravascular radiation therapy in rabbit iliac arteries. Circulation 2003;107:2153-8. 